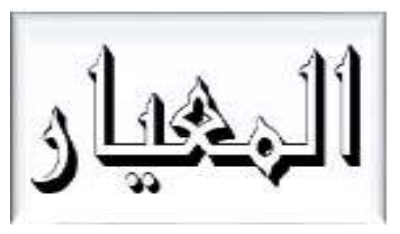

Al Mi'yar

Vol. 3, No. 1, April 2020

P-ISSN: 2620-6749, E-ISSN: 2620-6536

DOI: $10.35931 / a m . v 3 i 1.209$

\title{
PENGGUNAAN VLOG DALAM PEMBELAJARAN MAHĀRAH KALĀM
}

\author{
Mahfuz Rizqi Mubarak¹, Aulia Mustika Ilmiani², Nurul Wahdah³, Hamidah4
}

Institut Agama Islam Negeri Palangka Raya, Kalimantan Tengah, Indonesia Email: ${ }^{1}$ mahfuzrizqimubarak@iain-palangkaraya.ac.id, ${ }^{2}$ aulia.mustika.ilmiani@iainpalangkaraya.ac.id, ${ }^{3}$ nwahdah1980@gmail.com, ${ }^{4}$ hamidah@iain-palangkaraya.ac.id

\section{Abstract}

This study aims to explore the use of vlog in learning Mahārah kalām. The formulation of the problem in this study is: how to use Vlogs in learning Mahärah kalām and What is the perception of students regarding the use of Vlogs on learning Mahärah kaläm. This study uses descriptive qualitative research methods with trianguliation techniques namely observation, interviews, and documentation. The results revealed the use of Vlog /Vlogging in Mahärah kalām learning using the following steps: (1) Determination of the theme by lecturers supporting the course, (2) Preparation of ideas as material for making scripts/scenarios, (3) Site selection, (4) Evaluation of results, (5) and publication of Vlog video results on social media accounts. received a very positive response from students of the IAIN Palangka Raya Language Education Study Program. 28 out of 30 students gave positive responses regarding the use of Vlogs in the learning of Mahārah kalām. This positive response is based on several reasons: its use is easy, flexible, practical, and economical. Students are also required to be more creative in making vlogging videos so as to produce a good video. but the use of Vlog is also not free from negative responses such as cheating by students who seem to hide the text/script behind the camera so that the video presented is not entirely pure from the results of Mahārah kalām.

Keywords: Vlog, Mahārah kalām, College Studets

\section{PENDAHULUAN}

Di era globalisasi ini teknologi mengalami perkembangan yang sangat pesat. Tidak dapat dipungkiri bahwa teknologi pada era ini telah merambah begitu dalam terhadap berbagai aspek kehidupan manusia. Hal ini berimplikasi terhadap manusia yang masih gagap akan perkembangan 
teknologi maka posisinya termarginalkan dan terhempas pada gelombang globalisasi yang sarat dengan kompetisi ${ }^{1}$.

Perkembangan Teknologi juga merambah terhadap aktifitas sosial manusia. Aplikasi media sosial seperti Whatsapp, Facebook, Instagram, Twitter, Youtube, dan media sosial lainnya merupakan bentuk implikasi dari perkembangan teknologi yang mengarah kepada aktifitas sosial. Media-media tersebut memberikan kemudahan kepada manusia untuk saling berinteraksi sosial tanpa terhalang oleh ruang dan waktu.

Beberapa media sosial yang telah disebutkan sebelumnya juga telah merambah ke dunia Pendidikan. Sejauh ini sudah banyak penelitian yang membahas penggunaan media sosial dalam proses pembelajaran. Halimatus Sa'diyah mengungkapkan bahwa media Whatsapp berperan terhadap pertumbuhan kepecayaan diri mahasiswa untuk berkomunikasi menggunakan bahasa $\mathrm{Arab}^{2}$. pertumbuhan kepercayaan diri (self-confidence) tersebut dibuktikan dengan antusiasme mahasiswa dalam bentuk ungkapan-ungkapan pendapat dan komentar yang sangat variatif pada grup whatsapp. Begitu juga Albantani mengungkapkan bahwa media sosial elektronik seperti youtube, facebook, dan Instagram sebagai media alternatif dalam proses pembelajaran bahasa Arab. media sosial tersebut sangat mungkin meningkatkan motivasi belajar peserta didik baik dari jenjang dasar, jenjang menengah bahkan perguruan tinggi. Melalui media tersebut proses pembelajaran bahasa Arab menjadi sangat fleksibel karena dapat dilakukan di manapun dan kapanpun ${ }^{3}$. Dalam penelitiannya yang lain Albantani \& Ahmad Madkur mengungkapkan bahwa media Youtube menyediakan beragam sumber belajar menarik yang dapat dimanfaatkan untuk meningkatkan kemampuan bahasa Arab peserta didik. Terlepas dari kelebihan dan kekurangannya, Albantani \& Ahmad Madkur sangat merekomendasikan para pendidik untuk mendayagunakan youtube sebagai media pembelajaran yang efektif kususnya pada era abad 21

1 Haniah Haniah, "Pemanfaatan Teknologi Informasi Dalam Mengatasi Masalah Belajar Bahasa Arab," Al-Ta'rib: Jurnal Ilmiah Program Studi Pendidikan Bahasa Arab IAIN Palangka Raya 2, no. 1 (1 Juni 2014): 1, https://doi.org/10.23971/altarib.v2i1.588.

2 Halimatus Sa`diyah, "Upaya Menumbuhkan Self-Confidence Berbicara Bahasa Arab Mahasiswa Melalui Grup Whatsapp," Al Mi'yar: Jurnal Ilmiah Pembelajaran Bahasa Arab dan Kebahasaaraban 2, no. 2 (27 Juli 2019): 149, https://doi.org/10.35931/am.v2i2.119.

3 Azkia Muharom Albantani, "Social Media as Alternative Media for Arabic Teaching in Digital Era," ALSINATUNA 4, no. 2 (25 Juni 2019): 148, https://doi.org/10.28918/alsinatuna.v4i2.2043. 
seperti sekarang4.

Dari beberapa penelitian di atas, dapat disimpulkan bahwa perkembangan teknologi seperti media sosial memiliki pengaruh yang positif pada dunia Pendidikan. Media sosial menjadi media alternatif yang dapat digunakan oleh Pendidik pada kegiatan pembelajaran. Inovasi penggunaan media sosial ini sangat diperlukan mengingat data penelitian yang telah dilakukan Sekolah Tinggi Sandi Negara (STSN) Bersama Yahoo sebagaimana dikutip Wilga, dkk mengungkapkan bahwa Generasi muda mendominasi penggunaan internet di Indonesia sebanyak 64\%5.

Salah satu fitur yang populer dari media sosial sekarang ini adalah fitur video-blogging atau yang lebih dikenal dengan istilah vlog atau vlogging. Dalam beberapa tahun terakhir Vlogtelah mendapatkan banyak perhatian dari seluruh dunia terutama setelah perusahaan Google mengakusisi Youtube pada bulan November 2006 silam dengan kisaran harga USD 1,65 Miliar6. Fitur ini memungkinkan pengguna media sosial untuk melakukan aktifitas blog video seperti mereview suatu barang atau tempat yang sedang atau telah dikunjungi secara verbal dengan tambahan-tambahan informasi secara tertulis atau tampilan potongan gambar yang informatif7.

Di dunia Pendidikan fitur vlog mulai menampakkan eksistensinya sebagai salah satu media yang digunakan dalam kegiatan pembelajaran. Wulandari dalam penelitiannya mengungkapkan "Vlogging as an alternative oral communication strategy for improving English speaking skill is proven to be a fun and easy-to-access media"8. Fitur ini sebagai alternatif strategi komunikasi verbal dalam meningkatkan keterampilan berbahasa Inggris yang menyenangkan serta mudah diakses. Dia juga menambahkan "The Nature of

${ }^{4}$ Azkia Muharom Albantani dan Ahmad Madkur, "Musyahadat Al Fidyu: Youtube-Based Teaching and Learning of Arabic as Foreign Language (AFL)," Dinamika Ilmu 17, no. 2 (31 Desember 2017): 305, https://doi.org/10.21093/di.v17i2.854.

${ }^{5}$ Wilga Secsio Ratsja Putri, Nunung Nurwati, dan Meilanny Budiarti S, "Pengaruh Media Sosial Terhadap Perilaku Remaja," Prosiding Penelitian dan Pengabdian kepada Masyarakat 3, no. 1 (1 Januari 2016), https://doi.org/10.24198/jppm.v3i1.13625.

6 Wen Gao dkk., "Vlogging: A Survey of Videoblogging Technology on the Web," ACM Computing Surveys 42, no. 4 (1 Juni 2010): 1-57, https://doi.org/10.1145/1749603.1749606.

7 "Blog video," dalam Wikipedia bahasa Indonesia, ensiklopedia bebas, 19 Desember 2019, https://id.wikipedia.org/w/index.php?title=Blog_video\&oldid=16336132.

8 Eka Wulandari, "Improving Students' Speaking Ability through Vlogging" (UNNES International Conference on English Language Teaching, Literature, and Translation (ELTLT 2018), Atlantis Press, 2019), 27, https://doi.org/10.2991/eltlt-18.2019.5. 
young people today as digital native generation who likes to "perform" and "share" everything online makes vlogging becomes one of the best alternative for English speaking practice" 9 . Sifat anak muda saat ini sebagai generasi melek digital yang sangat aktif untuk tampil "perform" dan berbagi "share" segala aktifitas secara online di media sosial tentunya menjadikan vlog sebagai alternatif terbaik dalam mempraktikkan speaking skill dalam bahasa Inggris ${ }^{10}$. Penggunaan Vlog tidak hanya berimplikasi pada pertumbuhan motivasi mahasiswa dalam belajar saja, akan tetapi juga berpotensi pada pertumbuhan kesadaran akan kekayaan literasi digital (digital literacy skills), kepercayaan diri untuk berbicara di depan umum (speaking skills), serta keterampilan lintas budaya (intercultural skills) ${ }^{11}$.

Di IAIN Palangka Raya, salah satu Dosen menggunakan fitur vlog pada kegiatan pembelajaran mata kuliah Mahārah kalām. Mata kuliah ini diselenggarakan untuk mahasiswa Program Studi Pendidikan Bahasa Arab Semester Ganjil TA 2019/2020. Hal ini menarik untuk diteliti mengingat pembelajaran menggunakan fitur ini masih jarang ditemukan khususnya pada Pembelajaran Bahasa Arab.

Dari berbagaimacam penjelasan yang telah disebutkan sebelumnya, peneliti tertarik untuk mengeksplorasi lebih dalam tentang penggunaan Vlog yang diaplikasikan oleh Dosen pada kegiatan pembelajaran Mahārah kalām. Adapun rumusan masalah pada artikel ini adalah (1) bagaimana penggunaan Vlog pada pembelajaran Mahārah kalām? (2) Bagaimana persepsi mahasiswa mengenai penggunaan Vlog pada pembelajaran mahārah kalām?.

\section{METODE PENELITIAN}

Penelitian ini menggunakan penelitian kualitatif deskriptif. Penelitian kualitatif bertujuan untuk memperoleh informasi atau gambaran yang meliputi 3 aspek sosial seperti tempat, pelaku, dan aktifitas yang saling berinteraksi secara sinergis ${ }^{12}$. Deskriptif sebagai pemecah masalah yang akan diteliti dengan mendeskripsikan atau menggambarkan situasi-situasi pada

\footnotetext{
${ }^{9}$ Wulandari, 27.

${ }^{10}$ Wulandari, 27.

11 Christelle Combe dan Tatiana Codreanu, "Vlogging: A New Channel for Language Learning and Intercultural Exchanges," dalam CALL Communities and Culture - Short Papers from EUROCALL 2016, ed. oleh Salomi Papadima-Sophocleous, Linda Bradley, dan Sylvie Thouësny (Research-publishing.net, 2016), 123, https://doi.org/10.14705/rpnet.2016.eurocall2016.548.

12 Sugiyono, Metode Penelitian Pendidikan (Bandung: Alfabeta, 2015), 285.
} 
objek penelitian.

Akar masalah dari penelitian ini adalah tentang penggunaan Vlog pada kegiatan pembelajaran Mahārah kalām untuk mahasiswa Program Studi Pendidikan Bahasa Arab IAIN Palangka Raya semester Ganjil TA 2019-2020 dan bagaimana persepsi mereka perihal penggunaan Vlog tersebut dalam kegiatan pembelajaran.

Teknik pengumpulan data pada penelitian ini dilakukan dengan tehnik triangulasi yang terdiri observasi, wawancara, dan dokumentasi. Observasi dilakukan untuk pengamatan secara langsung kegiatan pembelajaran Mahārah kalām di lapangan. Wawancara langsung kepada Dosen yang bersangkutan sangat dibutuhkan untuk memperkuat hasil penelitian. Dokumentasi yang digunakan berupa angket hasil survey mahasiswa yang mengalami secara langsung penggunaan Vlog pada kegiatan pembelajaran Mahārah kalām. Dokumen angket akan sangat berguna untuk mengetahui persepsi mereka mengenai proses pembelajaran tersebut.



Gambar 1: Teknik Pengumpulan Data Menggunakan Triangulasi

\section{HASIL DAN PEMBAHASAN}

Berdasarkan paparan data dari hasil observasi, wawancara, dan dokumentasi secara langsung di lapangan, Peneliti menemukan beberapa topik pembahasan yang akan dikaji pada penggunaan vlog dalam pembelajaran mata kuliah mahārah kalām yang digunakan Dosen untuk mahasiswa Program Studi Pendidikan Bahasa Arab (PBA) IAIN Palangka Raya Semester Ganjil Tahun Akademik 2019/2020. Beberapa topik tersebut meliputi alasan Penggunaan 
Vlog, langkah-langkah penggunaan Vlog, dan persepsi mahasiswa mengenai pembelajaran Mahārah kalām menggunakan Vlog.

\section{Alasan Penggunaan Vlog pada Pembelajaran Mahārah kalām}

dari hasil wawancara, ada dua alasan dari penggunaan Vlog pada kegiatan Pembelajaran Mahārah kalām: Pertama, Vlog dan Mahārah kalām memiliki karakteristik yang sama. Vlogger ${ }^{13}$ umumnya mengekspresikan cerita atau opini mereka dalam sajian video review sebuah benda atau tempat dalam bentuk ujaran verbal/lisan. begitu juga Mahārah kalām berorientasi pada kemampuan mengungkapkan bunyi-bunyi artikulasi atau kata-kata untuk mengekspresikan ide, gagasan, pendapat, dan komunikasi secara verbal/lisan (شفهيا) Dosen berpandangan bahwa kesamaan karakteristik dari keduanya akan sangat menguntungkan baik bagi Dosen maupun mahasiswa untuk menyesuaikan diri pada proses pembelajaran Mahärah kalām. Di sisi lain, penggunaan Vlog pada pembelajaran tidak akan menyulitkan para mahasiswa karena hanya perlu menyiapkan HP yang sudah dilengkapi dengan kamera.

Kedua, Mahasiswa sering kali memanfaatkan kelengahan Dosen untuk mengoperasikan HP/gadget mereka di jam belajar. Mereka memanfaatkan kesempatan tersebut untuk sekedar membuka Media sosial seperti Whatsapp, Instagram, dan Facebook. Bahkan parahnya lagi, mereka memanfaatkan kelengahan tersebut untuk bermain game. Hal ini selaras dengan hasil laporan detiknet yang mengungkapkan bahwa para remaja cenderung menghabiskan waktu bersama gadget mereka untuk bermain game dan media sosial ${ }^{15}$ sehingga beberapa peneliti melabeli mereka dengan istilah Pro-Gadget ${ }^{16}$.

13 Sebutan bagi para pengguna video blog

${ }^{14}$ Gautama Veri Vetiana, "The Role of the Center for Language Improvement in Enhanching Speaking Skills of The Class One of The Modern Islamic Boarding School Darussalam Gontor at The Girls' Second Campuss (ar)," Al-Ta'rib : Jurnal Ilmiah Program Studi Pendidikan Bahasa Arab IAIN Palangka Raya 7, no. 2 (22 Desember 2019): 113, https://doi.org/10.23971/altarib.v7i2.1518.

15 Rahma Lillahi Sativa, "Berapa Lama Waktu Ideal Gunakan Gadget?," detikinet, diakses 25 Januari 2020, https://inet.detik.com/cyberlife/d-3398914/berapa-lama-waktu-idealgunakan-gadget.

16 Universitas Negeri Malang, Indonesia Dan Eka Dian Susanti, "Project Based Learning: Pemanfaatan Vlog Dalam Pembelajaran Sejarah Untuk Generasi Pro Gadget," Sejarah dan Budaya Jurnal Sejarah Budaya dan Pengajarannya 13, no. 1 (30 Juni 2019): 84-96, https://doi.org/10.17977/um020v13i12019p084. 
Fenomena ini menjadi pertimbangan besar bagi dosen pengampu mata kuliah Mahārah kalām untuk menggunakan vlog pada kegiatan pembelajaran guna meminimalisir kejadian tersebut.

Ketiga, Dosen pengampu mata kuliah Mahārah kalām menambahkan bahwa inisiatif dari penggunaan Vlog ini diharapkan dapat memberikan kesadaran terhadap mahasiswa bahwa fasilitas gadget tidak hanya sebatas untuk bermain game dan media sosial saja akan tetapi juga bermanfaat pada sesuatu yang bersifat edukatif. Dosen juga berharap dengan penggunaan Vlog ini dapat meningkatkan kepercayaan diri mereka untuk mengungkapkan ide dan gagasannya secara lisan di depan umum dengan menggunakan bahasa Arab.

Dari beberapa alasan tersebut, dapat disimpulkan bahwa ada 3 alasan dari penggunaan Vlog pada pembelajaran mata kuliah Mahārah kalām: (1) Kesamaan karakteristik antara Vlog dan Mahārah kalām yang mengarah kepada kemampuan verbal/lisan, (2) Candu mahasiswa terhadap gadget ke arah hal yang negatif seperti memanfaatkan kelengahan Dosen untuk bermain HP, (3) Untuk memberikan kesadaran kepada mahasiswa bahwa fasilitas gadget juga memiliki manfaat untuk Pendidikan.

\section{Langkah-Langkah Penggunaan Vlog pada Pembelajaran Mahārah kalām}

Sebelum masuk ke langkah-langkah penggunaan Vlog, Dosen mengungkapkan bahwa ada beberapa hal yang perlu diperhatikan dalam penggunaannya, yakni:

\section{Inspirasi}

Adapun Inspirasi penggunaan vlog ini tidak lepas dari 3 alasan pemilihan Vlog pada kegiatan pembelajaran Mahārah kalām yaitu (1) Kesamaan karakteristik antara Vlog dan Mahārah kalām yang mengarah kepada kemampuan verbal/lisan, (2) Candu mahasiswa terhadap gadget ke arah hal yang negatif seperti memanfaatkan kelengahan Dosen untuk bermain HP, (3) Untuk memberikan kesadaran kepada mahasiswa bahwa fasilitas gadget juga memiliki manfaat untuk Pendidikan.

\section{Tema}

Tema yang ditetapkan Dosen untuk mahasiswa pada kegiatan pembelajaran Mahārah kalām menggunakan Vlog yaitu الترويج عن شعبة تعليم 
(Promosi Program Studi Pendidikan Bahasa Arab). Dosen mengungkapan beberapa alasan dari pemilihan tema ini, yakni: (1) untuk mensosialisasikan Program Studi Pendidikan Bahasa Arab yang ada di kampus IAIN Palangka Raya; (2) sebagai wujud dari salah satu visi IAIN Palangka Raya yaitu: Terdepan, Mengandung harapan agar IAIN Palangka Raya selalu terdepan dalam transformasi keilmuan melalui pendekatan teknologi informasi pada struktur kelembagaan, sumber daya manusia dengan tetap menggali nilai-nilai kearifan lokal dalam menjawab tantangan zaman serta perkembangan teknologi yang semakin cepat ${ }^{17}$. Begitu juga dengan salah satu tujuan dari Program Studi Pendidikan Bahasa Arab (PBA) di IAIN Palangka Raya yaitu menghasilkan tenaga pendidik bahasa Arab yang mampu menerapkan dan mengembangkan strategi pembelajaran yang inovatif dan kreatif serta berteknologi pembelajaran yang mutakhir ${ }^{18}$.

\section{Skenario}

Pada penggunaan Vlog ini, Dosen memberikan kebebasan kepada mahasiswa untuk membuat alur skenarionya masing-masing. Hal ini sengaja dilakukan untuk mengukur sejauh mana kreatifitas mahasiswa dalam pembuatan video Vlog yang akan mereka tampilkan.

\section{Tempat}

Dosen memberikan kebebasan pada mahasiswa untuk memilih tempat yang akan digunakan pada pembuatan video Vlog selama tidak keluar dari tema yang digunakan pada pembelajaran Mahārah kalām.

Dari penjelasan tersebut, peneliti menyimpulkan bahwa beberapa hal yang telah disebutkan sebelumnya selaras dengan hasil penelitian Priana yang menyebutkan bahwa pemanfaatan media Vlog pada pembelajaran harus memperhatikan beberapa aspek berikut yakni: Inspirasi, Tema, Skenario, dan Tempat ${ }^{19}$.

17 "Visi IAIN Palangka Raya - SIDaKIP," diakses 26 Januari 2020, http://www.iainpalangkaraya.ac.id/data/profil-kampus/visi/.

18 "Visi, Misi, dan Tujuan Prodi PBA," diakses 26 Januari 2020, http://pba.ftik.iainpalangkaraya.ac.id/2015/06/visi-misi-dan-tujuan-prodi-pba.html.

19 Ronny Yudhi Septa Priana, "Pemanfaatan Vlog Sebagai Media Pembelajaran Teritegrasi Tekhnologi Informasi," Prosiding Seminar Nasional Pendidikan FKIP 1, no. 2 (30 Mei 2017), http://www.jurnal.untirta.ac.id/index.php/psnp/article/view/313-316. 


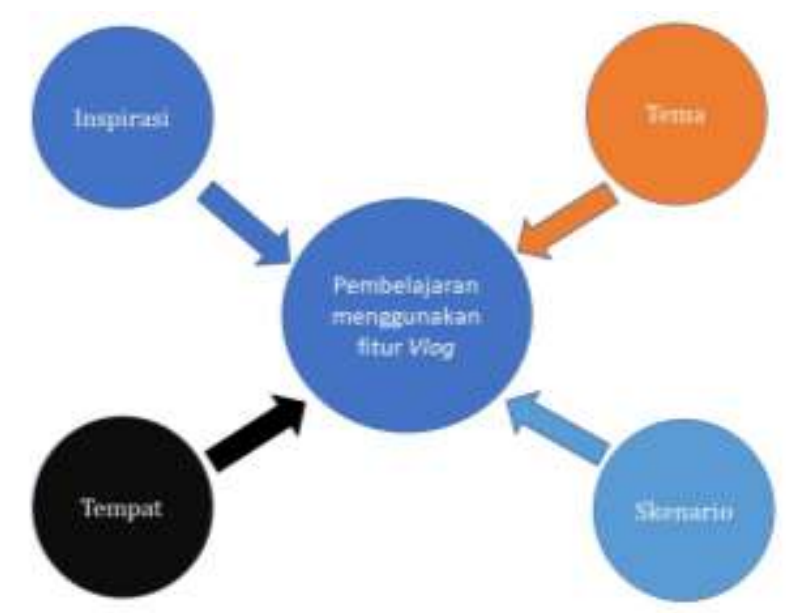

Gambar 2: aspek-aspek yang perlu diperhatikan pada penggunaan media Vlog

Dosen sebagai fasilitator dalam penggunaan Vlog memiliki peran yang sangat penting pada proses pembelajarannya. Berikut beberapa langkah yang digunakan Dosen pada pelaksanaan pembelajaran Mahārah kalām menggunakan Vlog:

Pertama, Dosen memberikan tema yang akan mahasiswa tampilkan di video Vlog. Tema yang ditentukan oleh Dosen adalah الترويج عن شعبة تعليم (Promosi Program Studi Pendidikan Bahasa Arab).

Kedua, mahasiswa diminta untuk menyusun ide dan gagasan mereka dalam bentuk skenario/naskah. Mahasiswa diberikan kebebasan untuk membuat konsep skenario selama tidak keluar dari tema yang telah ditentukan sebelumnya. Kebebasan dalam membuat skenario akan berdampak pada kreatifitas mahasiswa untuk menghasilkan sebuah video Vlog.

Ketiga, Mahasiswa diminta untuk mencari lokasi/tempat yang akan mereka gunakan pada pembuatan video Vlog. Lokasi yang akan dipilih mahasiswa adalah lokasi-lokasi yang menunjang daya tarik pembelajaran bahasa Arab di kampus IAIN Palangka Raya seperti laboratorium bahasa, perpustakaan, atau kantor Prodi PBA. Umumnya mayoritas Mahasiswa memilih lokasi laboratorium bahasa dengan alasan fasilitas media yang tersedia di laboratorium sangat relevan dengan tema yang digunakan dan menunjang proses pembuatan konsep skenario. Hal ini selaras dengan hasil penelitian salah satu dosen IAIN Palangka Raya bahwa laboratorium bahasa 
akan sangat menunjang pada pembelajaran bahasa Arab jika dimanfaatkan secara optimal20. Di sisi lain Dosen juga juga memberi kebebasan kepada mahasiswa untuk memilih lokasi di luar lingkungan kampus. Dosen beranggapan hal ini dapat mengembangkan kreatifitas mereka untuk mengintegrasikan bahasa Arab dengan kondisi sosial di masyarakat.

Keempat. Mahasiswa mulai action untuk membuat video Vlog berdasarkan tema yang telah ditentukan Dosen, skenario yang telah disusun sebelumnya, dan tempat yang telah mereka pilih. Dosen memberikan waktu pembuatan video Vlog selama satu minggu. pemberian waktu ini sangat diperlukan agar mahasiswa tidak terburu-buru dalam pembuatan video Vlog dan menghindari asumsi "yang penting selesai" sehingga menghasilkan video Vlog yang bagus dan menarik untuk dipublikasi di media sosial.

Kelima, Mahasiswa diminta mengumpulkan hasil video Vlog yang telah mereka buat kepada Dosen di pertemuan selanjutnya untuk dievaluasi. Evaluasi Mahārah kalām dilihat pada beberapa aspek berikut, yakni: pelapalan, tata bahasa, dan kelancaran. (1) Pelapalan secara verbal/lisan (شفهيا) seperti mengekspresikan ide, gagasan, atau pendapat, (2) tata bahasa mengarah kepada susunan Tarakib seperti Fi'iliyah (فعلية) dan Ismiyah (اسمياة)., (3) Kelancaran pada penyampaian ide dan gagasan menggunakan bahasa Arab. selain evaluasi pada Mahārah kalām, Dosen juga menilai kreatifitas mahasiswa dalam menyajikan sebuah video Vlog. Hasil video yang menarik akan meningkatkan daya tarik tersendiri bagi masyarakat khususnya untuk belajar bahasa Arab.

${ }^{20}$ Ahmadi Ahmadi, “Optimalisasi Pemanfaatan Laboratorium Bahasa Dalam Meningkatkan Pembelajaran Bahasa Arab," Al-Ta'rib: Jurnal Ilmiah Program Studi Pendidikan Bahasa Arab IAIN Palangka Raya 2, no. 1 (2014): 67-74, https://doi.org/10.23971/altarib.v2i1.1534. 




Gambar 3: evaluasi pada pembelajaran Mahārah kalām menggunakan Vlog

Keenam, hasil video Vlog mahasiswa yang paling bagus akan diupload di akun sosial media Program Studi PBA. Hal ini sebagai apresiasi Dosen terhadap hasil kerja keras mereka dalam menghasilkan video Vlog yang kreatif. Dosen juga mempersilahkan kepada semua Mahasiswa untuk mengupload hasil video Vlog di akun media sosial mereka masing-masing.

Dari beberapa penjelasan berikut, dapat disimpulkan bahwa langkahlangkah penggunaan Vlog pada pembelajaran Mahārah kalām terdiri dari: (1) Penentuan tema oleh Dosen pengampu mata kuliah Mahārah kalām, (2) Penyusunan ide/gagasan untuk pembuatan naskah/skenario, (3) Pemilihan tempat untuk pembuatan video Vlog, (4) Evaluasi hasil, (5) dan publikasi hasil video Vlog di akun media sosial. dari langkah-langkah ini, dapat dilihat bahwa Dosen memiliki peran penting untuk mengontrol hasil pembelajaran menggunakan Vlog. Dosen memang membatasi pada satu tema saja, namun tidak membatasi kreatifitas mahasiswa dengan memberikan kebebasan terhadap pembuatan naskah/skenario dan pemilihan tempat untuk menghasilkan video Vlog yang maksimal. hal ini senada dengan hasil penelitian Susanti mengenai pemanfaatan Vlog pada pembelajaran bahwa pendidik sebagai fasilitator dalam pemanfaatan Vlog sangat beperan penting. 
Pendidik harus dapat mengontrol tugas peserta didik dari awal namun tidak membatasi kreatifitas mereka dalam menghasilkan video Vlog 21.

\section{Persepsi Mahasiswa Mengenai Penggunaan Vlog pada Pembelajaran Mahārah kalām}

Selain dari Dosen, peneliti juga mengumpulkan hasil responden sebanyak 30 mahasiswa Progam Studi Pendidikan Bahasa Arab (PBA) Semester Ganjil TA 2019/2020 melalui angket yang disebarkan via google form. Angket terdiri dari 4 soal. 1 soal dengan pilihan jawaban seperti Sangat Setuju (SS), Setuju (S), Tidak Setuju (TS), dan Sangat Tidak Setuju (STS). dan 3 soal dengan jawaban deskriptif. Peneliti mengkategorikan jawaban SS dan S sebagai tanggapan positif. Sedangkan jawaban TS dan STS dikategorikan sebagai tanggapan negatif.

\begin{tabular}{|c|l|c|c|c|c|}
\hline No & \multicolumn{1}{|c|}{ Soal } & \multicolumn{3}{|c|}{ Jawaban } \\
\hline 1 & $\begin{array}{l}\text { Bagaimana pendapat anda mengenai Penggunaan } \\
\text { video Vlog pada pembelajaran Mahārah kalām? }\end{array}$ & SS & S TS & STS \\
\hline 2 & Berikan alasan anda! & & & \\
\hline 3 & $\begin{array}{l}\text { Apa Kelebihan dari penggunaan Vlog pada } \\
\text { pembelajaran Mahārah kalām? }\end{array}$ & & & \\
\hline 4 & $\begin{array}{l}\text { Apa Kekurangan dari penggunaan Vlog pada } \\
\text { pembelajaran Mahārah kalām? }\end{array}$ & & & \\
\hline
\end{tabular}

Tabel 1: Angket Kepuasaan Mahasiswa tentang Penggunaan Vlog

Berikut diagram hasil tanggapan mahasiswa mengenai penggunaan Vlog pada pembelajaran Mahārah kalām:

30 tanggapan

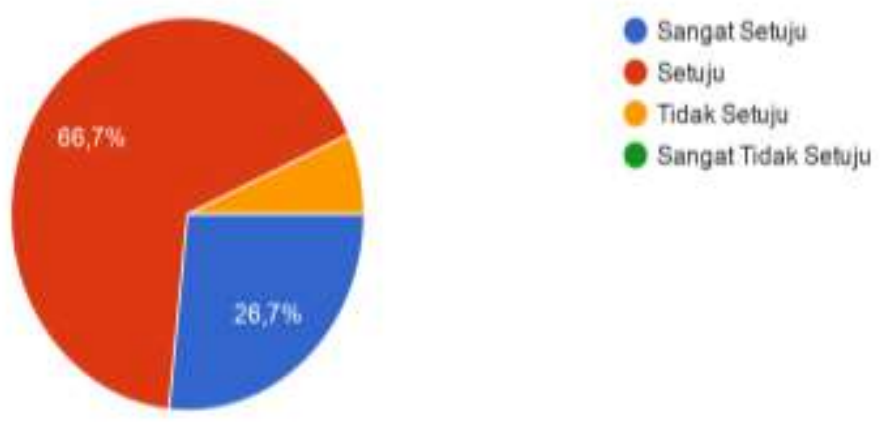

Gambar 4: Diagram hasil tanggapan angket mahasiswa

${ }^{21}$ Universitas Negeri Malang, Indonesia dan Susanti, "PROJECT BASED LEARNING.” 
Dari hasil diagram tersebut dapat disimpulkan bahwa mahasiswa yang memberikan tanggapan sangat setuju (SS) sebanyak 8 mahasiswa $(26,7 \%)$, tanggapan setuju (S) sebanyak 20 mahasiswa $(66,7 \%)$, tanggapan tidak setuju (TS) sebanyak 2 mahasiswa (6,7\%), dan tanggapan sangat tidak setuju (STS) sebanyak 0 mahasiswa (0\%). Dari hasil tanggapan 30 mahasiswa, sebanyak 28 mahasiswa memberikan tanggapan positif dan hanya 2 mahasiswa yang memberikan tanggapan negatif. Berikut kesimpulan hasil tanggapan mahasiswa:

\section{Tanggapan Positif}

Dalam penelitian ini, peneliti menyimpulkan beberapa tanggapan positif yang dihimpun dari 30 responden mahasiswa sebagai berikut: mahasiswa beranggapan bahwa penggunaan vlog ini sangat membantu dalam meningkatkan kepercayaan diri mahasiswa untuk lebih aktif bebicara berbahasa Arab. pemanfaatannya pun mudah, fleksibel, praktis dan ekonomis karena hanya cukup bermodalkan teknologi Gadget yang sudah difasilitasi teknologi kamera. Di sisi lain mahasiswa juga beranggapan bahwa penggunaan Vlog ini membantu mahasiswa untuk lebih kreatif dalam menampilkan hasil video vlogging yang akan mereka posting di media sosial. Bagi mahasiswa, kreatifitas hasil video yang akan ditampilkan berdampak pada motivasi para penonton untuk belajar bahasa Arab.

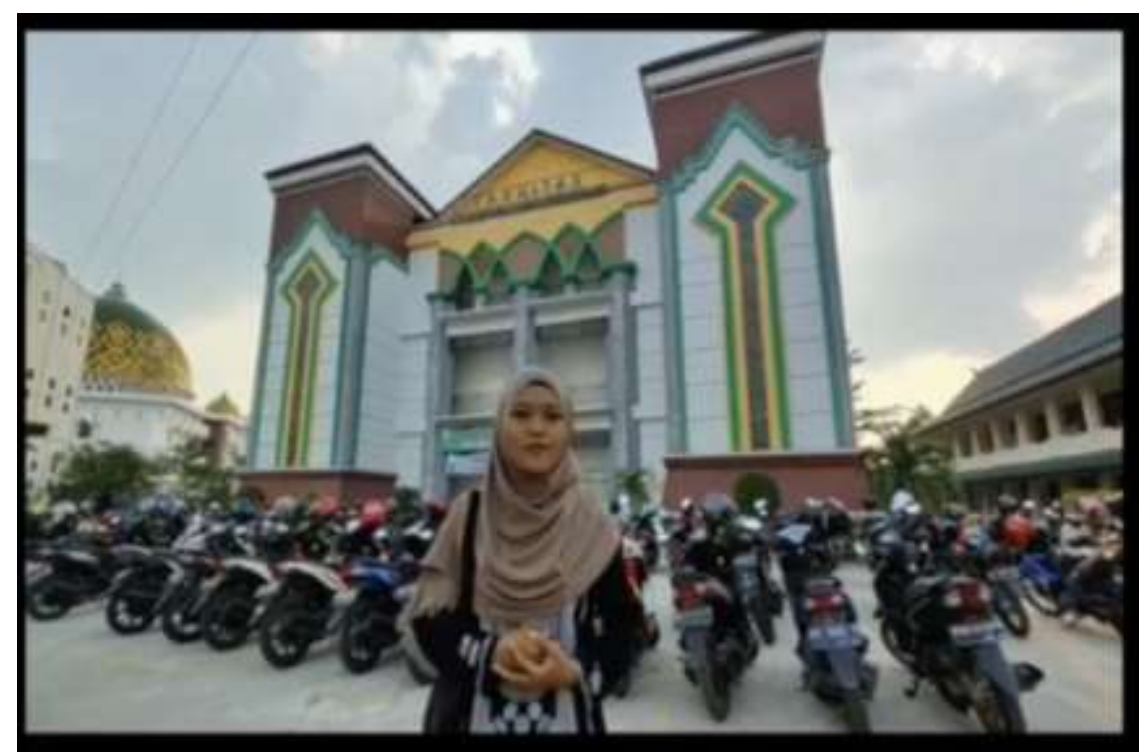

Gambar 5: hasil video vlogging mahasiswa PBA IAIN Palangka Raya 


\section{Tanggapan Negatif}

Namun, penggunaan Vlog pada pembelajaran mahārah kalām ini juga tidak lepas dari kekurangan. Peneliti menemukan beberapa tanggapan negatif dari hasil angket yang peneliti sebarkan melalui Google Form.

Seperti yang telah disebutkan bahwa penggunaan Vlog ini sangat mudah dan fleksibel. Namun beberapa mahasiswa cenderung memanfaatkan kefleksibelan ini ke hal yang negatif. Beberapa mahasiswa mengungkapkan bahwa penggunaan Vlog rentan terjadi kecurangan. Bentuk kecurangan tersebut seperti menyembunyikan teks/naskah di belakang kamera sehingga hasil cerita yang ditampilkan di video tidak murni dari hasil kalam melainkan hasil dari membaca. Beberapa mahasiswa juga mengungkapkan bahwa hasil kalam yang ditampilkan di video vlogging rentan mengalami kesalahan berbahasa khususnya pada aspek Qawāid (Nahwu dan Sharf). Terlepas dari tanggapan-tanggapan negatif tersebut bahwa penggunaan Vlog pada kegiatan pembelajaran Mahārah kalām ini memiliki nilai yang positif untuk meningkatkan kepercayaan diri mahasiswa dalam mengembangkan kompetensi mereka di Mahārah Kalām. Fitur yang praktis, fleksibel, dan ekonomis serta up to date sangat selaras dengan karakter mahasiswa zaman sekarang yang kesehariannya tidak akan lepas dari teknologi gadget.

\section{SIMPULAN}

Dari penelitian ini peneliti menyimpulkan beberapa point berikut: Beberapa alasan mengenai pemilihan penggunaan Vlog pada pembelajaran Mahārah kalām, yakni (1) Kesamaan karakteristik antara Vlog dan Mahārah kalām, (2) candu mahasiswa terhadap penggunaan Gadget yang berimplikasi pada tingkah laku yang buruk seperti memanfaatkan kelengahan Dosen untuk bermain HP, (3) Memberikan kesadaran terhadap mahasiswa agar memanfaatkan fasilitas gadget untuk Pendidikan. Adapun langkah-langkah dari penggunaan Vlog pada pembelajaran Mahārah kalām, yakni (1) Penentuan tema oleh Dosen pengampu mata kuliah, (2) Penyusunan ide/gagasan sebagai bahan pembuatan naskah/skenario, (3) Pemilihan tempat, (4) Evaluasi hasil, (5) dan publikasi hasil video Vlog di akun media sosial. 28 dari 30 mahasiswa memberikan tanggapan positif mengenai penggunaan Vlog pada pembelajaran Mahārah kalām. 


\section{SARAN}

Peneliti berharap bahwa hasil penelitian ini berkontribusi pada wawasan baru khususnya para Pendidik (Guru maupun Dosen) Bahasa Arab untuk lebih kreatif dan inovatif dalam pelaksanaan KBM (Kegiatan Belajar Mengajar) sehingga tidak terjadi proses pembelajaran yang monoton. Penggunaan Vlog ini tergolong mudah dikarenakan hanya cukup menyediakan HP yang sudah difasilitasi kamera dan mudah didapatkan dengan harga terjangkau. Peneliti juga berharap agar penelitian ini dapat dijadikan acuan untuk penelitian-penelitian selanjutnya yang berorientasi pada kreatifitas seorang pendidik di kegiatan pembelajaran Bahasa Arab.

\section{DAFTAR PUSTAKA}

Ahmadi, Ahmadi. "Optimalisasi Pemanfaatan Laboratorium Bahasa Dalam Meningkatkan Pembelajaran Bahasa Arab." Al-Ta'rib: Jurnal Ilmiah Program Studi Pendidikan Bahasa Arab IAIN Palangka Raya 2, no. 1 (2014): 67-74. https://doi.org/10.23971/altarib.v2i1.1534.

Albantani, Azkia Muharom. "Social Media as Alternative Media for Arabic Teaching in Digital Era." ALSINATUNA 4, no. 2 (25 Juni 2019): 148-61. https://doi.org/10.28918/alsinatuna.v4i2.2043.

Albantani, Azkia Muharom, dan Ahmad Madkur. "Musyahadat Al Fidyu: Youtube-Based Teaching and Learning of Arabic as Foreign Language (AFL)." Dinamika Ilmu 17, no. 2 (31 Desember 2017): 291-308. https://doi.org/10.21093/di.v17i2.854.

"Blog video." Dalam Wikipedia bahasa Indonesia, ensiklopedia bebas, 19 Desember 2019.

https://id.wikipedia.org/w/index.php?title=Blog_video\&oldid=1633613 2.

Combe, Christelle, dan Tatiana Codreanu. "Vlogging: A New Channel for Language Learning and Intercultural Exchanges." Dalam CALL Communities and Culture - Short Papers from EUROCALL 2016, disunting oleh Salomi Papadima-Sophocleous, Linda Bradley, dan Sylvie Thouësny, 119-24. Research-publishing.net, 2016. https://doi.org/10.14705/rpnet.2016.eurocall2016.548. 
Gao, Wen, Yonghong Tian, Tiejun Huang, dan Qiang Yang. "Vlogging: A Survey of Videoblogging Technology on the Web." ACM Computing Surveys 42, no. 4 (1 Juni 2010): 1-57. https://doi.org/10.1145/1749603.1749606.

Haniah, Haniah. "Pemanfaatan Teknologi Informasi Dalam Mengatasi Masalah Belajar Bahasa Arab." Al-Ta'rib: Jurnal Ilmiah Program Studi Pendidikan Bahasa Arab IAIN Palangka Raya 2, no. 1 (1 Juni 2014). https://doi.org/10.23971/altarib.v2i1.588.

Priana, Ronny Yudhi Septa. "Pemanfaatan Vlog Sebagai Media Pembelajaran Teritegrasi Tekhnologi Informasi." Prosiding Seminar Nasional Pendidikan FKIP 1, no. 2 (30 Mei 2017). http://www.jurnal.untirta.ac.id/index.php/psnp/article/view/313-316.

Putri, Wilga Secsio Ratsja, Nunung Nurwati, dan Meilanny Budiarti S. "Pengaruh Media Sosial Terhadap Perilaku Remaja." Prosiding Penelitian dan Pengabdian kepada Masyarakat 3, no. 1 (1 Januari 2016). https://doi.org/10.24198/jppm.v3i1.13625.

Sa’diyah, Halimatus. "Upaya Menumbuhkan Self-Confidence Berbicara Bahasa Arab Mahasiswa Melalui Grup Whatsapp." Al Mi'yar: Jurnal Ilmiah Pembelajaran Bahasa Arab dan Kebahasaaraban 2, no. 2 (27 Juli 2019): 149-64. https://doi.org/10.35931/am.v2i2.119.

Sativa, Rahma Lillahi. “Berapa Lama Waktu Ideal Gunakan Gadget?” detikinet. Diakses 25 Januari 2020. https://inet.detik.com/cyberlife/d3398914/berapa-lama-waktu-ideal-gunakan-gadget.

Sugiyono. Metode Penelitian Pendidikan. Bandung: Alfabeta, 2015.

Universitas Negeri Malang, Indonesia, dan Eka Dian Susanti. “Project Based Learning: Pemanfaatan Vlog Dalam Pembelajaran Sejarah Untuk Generasi Pro Gadget." Sejarah dan Budaya Jurnal Sejarah Budaya dan Pengajarannya 13, no. 1 (30 Juni 2019): 84-96. https://doi.org/10.17977/um020v13i12019p084.

Vetiana, Gautama Veri. "The Role of the Center for Language Improvement in Enhanching Speaking Skills of The Class One of The Modern Islamic Boarding School Darussalam Gontor at The Girls' Second Campuss (ar)." Al-Ta'rib: Jurnal Ilmiah Program Studi Pendidikan Bahasa Arab IAIN 
Mahfuz Rizqi Mubarak, dkk: Penggunaan Vlog Dalam Pembelajaran Mahārah Kalām

Palangka Raya 7, no. 2 (22 Desember 2019): 111-20. https://doi.org/10.23971/altarib.v7i2.1518.

"Visi IAIN Palangka Raya - SIDaKIP." Diakses 26 Januari 2020. http://www.iain-palangkaraya.ac.id/data/profil-kampus/visi/.

"Visi, Misi, dan Tujuan Prodi PBA." Diakses 26 Januari 2020. http://pba.ftik.iain-palangkaraya.ac.id/2015/06/visi-misi-dan-tujuanprodi-pba.html.

Wulandari, Eka. "Improving Students' Speaking Ability through Vlogging." Atlantis Press, 2019. https://doi.org/10.2991/eltlt-18.2019.5. 
Mahfuz Rizqi Mubarak, dkk: Penggunaan Vlog Dalam Pembelajaran Mahārah Kalām

Jurnal Al Mi'yar Vol. 3, No. 1 April 2020

Homepage https://jurnal.stiq-amuntai.ac.id/index.php/al-miyar 